\title{
Investigating the contribution of claystone to the swelling pressure of its mixture with bentonite
}

\author{
Zhixiong Zeng ${ }^{1, *}, Y u-J u n \mathrm{Cui}^{1}$, Nathalie Conil $^{2}$, and Jean Talandier ${ }^{3}$ \\ ${ }^{1}$ Ecole des Ponts ParisTech, Laboratoire Navier/CERMES, 6 et 8 avenue Blaise Pascal, 77455 Marne La Vallée cedex 2, France \\ ${ }^{2}$ Andra, Centre de Meuse/Haute-Marne, RD 960, 55290 Bure, France \\ ${ }^{3}$ Andra, 1/7, rue Jean Monnet, 92298 Châtenay-Malabry cedex, France
}

\begin{abstract}
Compacted MX80 bentonite/Callovo-Oxfordian (COx) claystone mixture has been considered as a possible sealing/backfilling material in the French deep geological radioactive waste disposal. The swelling pressure of such mixture is an important factor in the design and long-term safety assessment of deep geological repositories. In this study, constant-volume swelling pressure tests were performed on the mixtures with different claystone fractions and dry densities. The test results show that the swelling pressure of the mixtures decreased with the increasing claystone fraction and decreasing dry density. According to the experimental results, the contribution of claystone to the global swelling pressure was further investigated. It was found that the deformation of claystone and its contribution to swelling pressure was highly dependent on the claystone fraction. As the claystone fraction was larger than $30 \%$, the claystone in the mixture swelled, contributing to the global swelling pressure; On the contrary, as the claystone fraction was less than $30 \%$, the swelling of claystone was inhibited by the bentonite and it worked an inert material without any contribution to the swelling pressure.
\end{abstract}

\section{Introduction}

In the French design of deep geological disposal for radioactive waste, the Callovo-Oxfordian (COx) claystone, an indurated clay rock 155 million years old (limit upper-middle Jurassic), is considered as a possible host rock by the French National Agency for Nuclear Waste Management (ANDRA) [1]. To access the reliability of a deep repository for radioactive waste in this clay-rich formation, an underground research laboratory (URL) has been excavated at a depth of around $490 \mathrm{~m}$ in the Eastern part of France. During the construction of this laboratory, enormous tunnel excavations produced large amounts of excess claystone to be dealt with. To reduce the excavation waste and to better ensure the compatibility of chemistry with the host rock, a mixture of excavated claystone and bentonite has been proposed to construct the sealing/backfilling elements. Once the repository is closed and local groundwater conditions are re-established, the bentonite/claystone mixture will be saturated by the groundwater from the host rock and generate a swelling pressure. This swelling pressure must high enough to limit the convergence of the galleries after the concrete lining failure [2], but lower than the yield stress supported by the plugs [3]. Therefore, a good understanding of the swelling behaviour of bentonite/claystone mixture is of great importance in the design and long-term safety of repositories.
In the past decades, the swelling pressure of pure bentonite and its mixture with sand has been studied by several investigators [3-8]. They pointed out that the swelling pressure of bentonite-based materials was mainly dependent on the bentonite dry density. Unlike sand, COx claystone was characterized by a large fraction of clay minerals, which could absorb water and swell [9]. Wang et al. [10] found that the claystone worked as an inert material and had a negligible contribution to the global swelling pressure when they investigated the swelling pressure of MX80 bentonite/COx claystone mixture with a bentonite fraction of $70 \%$. However, the role and contribution of claystone to the swelling pressure of bentonite/COx claystone mixture with more claystone have not been validated.

In this work, a series of constant-volume swelling pressure tests were carried out on the MX80 bentonite/COx claystone mixtures with different bentonite fractions and dry densities $\left(\rho_{\mathrm{dm}}\right)$. The role and contribution of claystone on the global swelling pressure of its mixture with bentonite were further investigated.

\section{Materials and methods}

Studied soil was a mixture of MX80 bentonite and COx claystone. The bentonite was collected from Wyoming, USA, with a large montmorillonite content (92\%). The bentonite is characterized by a liquid limit of $575 \%$, a 
plastic limit of $53 \%$, a hygroscopic water content of $11.4 \%$, a bulk density of $2.0 \mathrm{Mg} / \mathrm{m}^{3}$ and a specific gravity of 2.76 [11-12]. The COx claystone was extracted from the ANDRA URL URL. Its main minerals are $40-45 \%$ clay minerals (mainly interstratified illite-smectite), 30\% carbonates and 2-30\% quartz and feldspar. Its hygroscopic water content, bulk density and specific gravity are $6.1 \%, 2.31 \mathrm{Mg} / \mathrm{m}^{3}$ and 2.70 , respectively [13]. Prior to laboratory testing, the bentonite and claystone were crushed to maximum grain sizes of $2.0 \mathrm{~mm}$.

The swelling pressure tests were performed on compacted samples. The bentonite and claystone powders, at hygroscopic water contents, were first carefully mixed with proportions of 70/30, 50.50, 30/70, 20/80, 10/90 and 0/100 in dry mass. Then, they were statically compacted in a rigid mould $(50 \mathrm{~mm}$ in inner diameter) at a controlled displacement rate of 0.05 $\mathrm{mm} / \mathrm{min}$ to reach different dry densities (Table 1 ). The target samples were $50 \mathrm{~mm}$ in diameter and $10 \mathrm{~mm}$ in height. Afterwards, the samples were introduced into a constant-volume cell and hydrated by synthetic water. During hydration, the axial swelling pressure was monitored. More details about the experimental set-up and the synthetic water are indicated by Zeng et al. [12].

Table 1. Test program and main results (dry density of sample $\rho_{\mathrm{dm}}$; initial water content $w_{\mathrm{m}}$; final swelling pressure $P_{\mathrm{s}}$ ).

\begin{tabular}{|c|c|c|c|c|}
\hline No. & $B(\%)$ & $\rho_{\mathrm{dm}}\left(\mathrm{Mg} / \mathrm{m}^{3}\right)$ & $w_{\mathrm{m}}(\%)$ & $P_{\mathrm{s}}(\mathrm{MPa})$ \\
\hline 01 & 70 & 1.38 & 9.8 & 0.43 \\
\hline 02 & 70 & 1.50 & 9.8 & 1.11 \\
\hline 03 & 70 & 1.63 & 9.8 & 2.53 \\
\hline 04 & 70 & 1.71 & 9.8 & 3.94 \\
\hline 05 & 50 & 1.27 & 8.8 & 0.13 \\
\hline 06 & 50 & 1.56 & 8.8 & 0.85 \\
\hline 07 & 50 & 1.73 & 8.8 & 2.10 \\
\hline 08 & 50 & 1.76 & 8.8 & 2.91 \\
\hline 09 & 30 & 1.50 & 7.7 & 0.22 \\
\hline 10 & 30 & 1.60 & 7.7 & 0.46 \\
\hline 11 & 30 & 1.68 & 7.7 & 0.78 \\
\hline 12 & 30 & 1.79 & 7.7 & 1.59 \\
\hline 13 & 30 & 1.89 & 7.7 & 2.72 \\
\hline 14 & 30 & 1.99 & 7.7 & 5.23 \\
\hline 15 & 20 & 1.60 & 7.2 & 0.26 \\
\hline 16 & 20 & 1.69 & 7.2 & 0.44 \\
\hline 17 & 20 & 1.77 & 7.2 & 0.70 \\
\hline 18 & 20 & 1.88 & 7.2 & 1.93 \\
\hline 19 & 10 & 1.61 & 6.6 & 0.14 \\
\hline 20 & 10 & 1.68 & 6.6 & 0.23 \\
\hline 21 & 10 & 1.78 & 6.6 & 0.39 \\
\hline 22 & 10 & 1.90 & 6.6 & 1.07 \\
\hline 23 & 0 & 1.80 & 6.1 & 0.15 \\
\hline 24 & 0 & 1.90 & 6.1 & 0.47 \\
\hline 25 & 0 & 1.99 & 6.1 & 0.79 \\
\hline
\end{tabular}

\section{Experimental results and discussions}

\subsection{Experimental results}

The typical evolution curves of swelling pressure for the samples with different bentonite fractions and dry densities are shown in Fig. 1. Overall, for the samples with high bentonite fractions (larger than 50\%) and high dry densities (larger than $1.50 \mathrm{Mg} / \mathrm{m}^{3}$ ), the swelling pressure increased and then reached a stabilization value. For the samples with low bentonite fractions (smaller than 20\%) and low dry densities (smaller than 1.77 $\mathrm{Mg} / \mathrm{m}^{3}$ ), the swelling pressure increased at the beginning, reached a peak and decreased to a stabilization value. This peak could be related to the collapse of macro-pores. Because the COx claystone had a larger bulk density than the MX80 bentonite, more macro-pores could be expected in the samples with a large proportion of claystone and more significant collapse was observed.

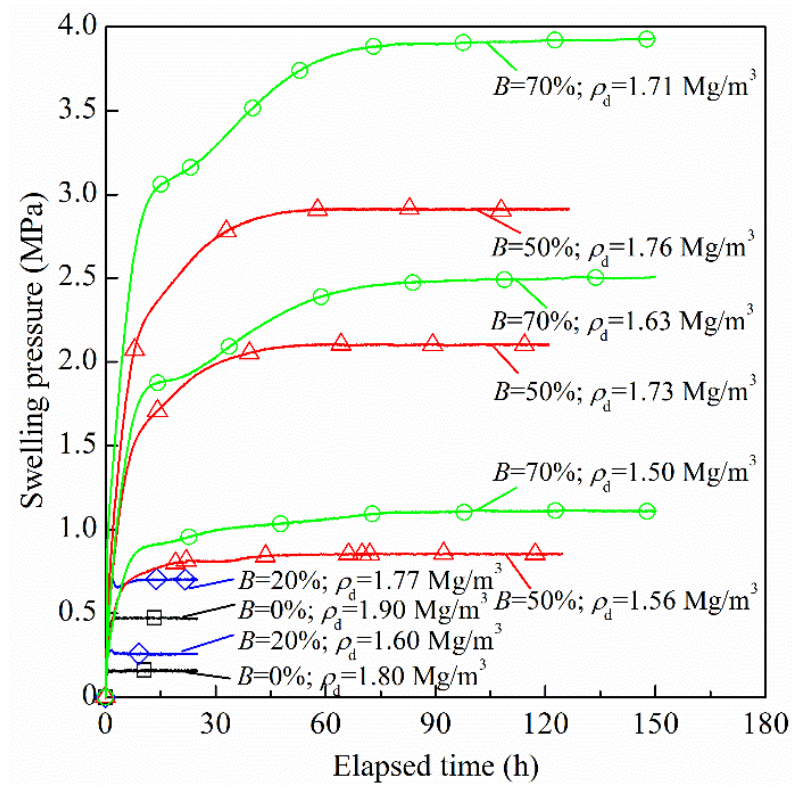

Fig. 1. Typical evolution curves of swelling pressure for the samples with different bentonite fractions and dry densities.

The final swelling pressures of samples are summarized in Table 1 and Fig. 2. The results of Karland et al. [4] on pure MX80 bentonite, Tang et al. [9] on pure COx claystone, Wang et al. [10] and Zhang et al. [14] on MX80 bentonite/COx claystone mixtures are also presented. A linear relationship could be identified between the logarithm of final swelling pressure and the dry density of samples. The slope for different bentonite fractions kept almost constant, while the intercept decreased with the decrease of bentonite fraction. At the same dry density, the final swelling pressure of bentonite/claystone mixture after saturation was much lower than that of pure bentonite, indicating that the addition of claystone weakened the global swelling capability. 


\subsection{Contribution of claystone to swelling pressure}

Basically, from the overall parameters, local variables for bentonite and additive (crushed COx or sand) could be defined and computed. Because of the large bulk density of additive, the mixing of the minerals in the bentonite and additive could not occur, at least in short term. For simplification, each bentonite-based mixture after full saturation could be divided into four parts: bentonite, voids in bentonite, additive and voids in additive, as shown in Fig. 3 [10, 15].

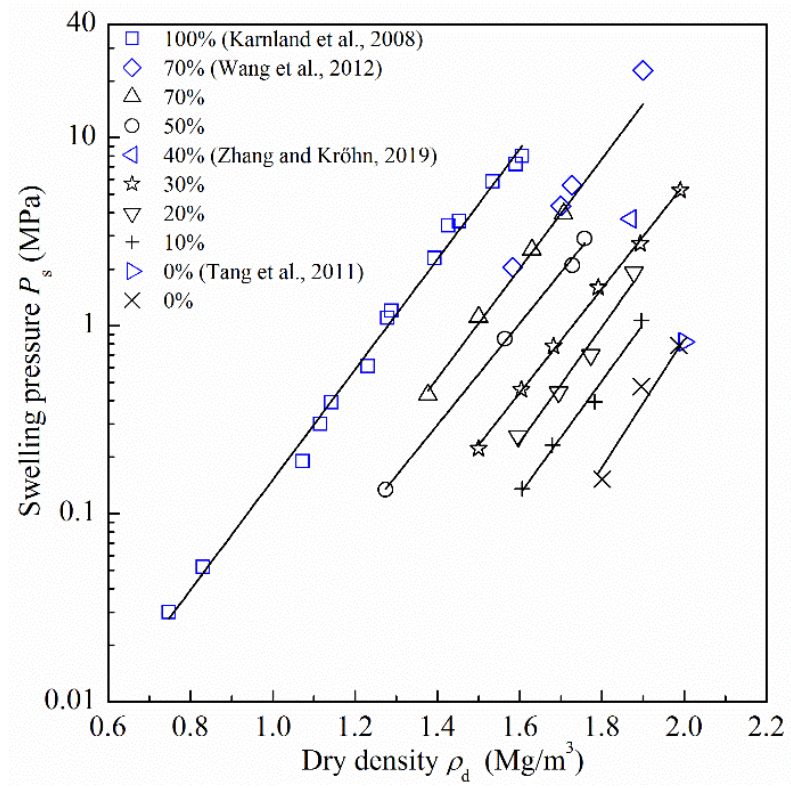

Fig. 2. Relationship between the final swelling pressure and dry density of samples.

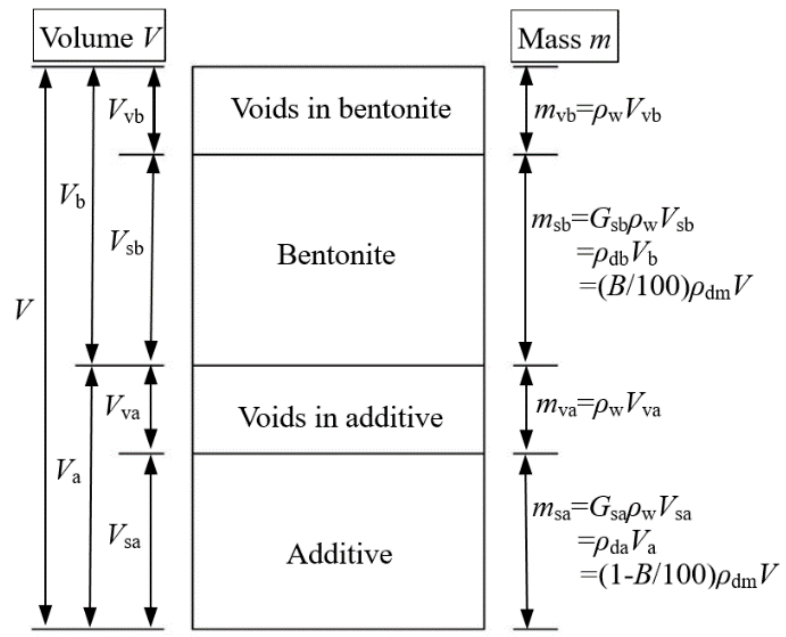

Fig. 3. Composition of bentonite/additive mixture.

The bentonite dry density $\left(\rho_{\mathrm{db}}\right)$ can be calculated by the following equation:

$$
\rho_{\mathrm{db}}=\frac{(B / 100) \rho_{\mathrm{m}} G_{\mathrm{sa}} \rho_{\mathrm{w}}}{G_{\mathrm{sa}} \rho_{\mathrm{w}}\left(1+w_{\mathrm{m}} / 100\right)-\rho_{\mathrm{m}}(1-B / 100)\left(1+G_{\mathrm{sa}} w_{\mathrm{a}}\right)}
$$

$$
=\frac{(B / 100) \rho_{\mathrm{dm}} G_{\mathrm{sa}} \rho_{\mathrm{w}}}{G_{\mathrm{sa}} \rho_{\mathrm{w}}-\rho_{\mathrm{dm}}(1-B / 100)\left(1+G_{\mathrm{sa}} w_{\mathrm{a}}\right)}
$$

where $\rho_{\mathrm{m}}\left(\mathrm{Mg} / \mathrm{m}^{3}\right)$ is the mixture density; $\rho_{\mathrm{dm}}\left(\mathrm{Mg} / \mathrm{m}^{3}\right)$ is the dry density of the mixture; $\rho_{\mathrm{w}}$ is the water unit mass; $B(\%)$ is the bentonite fraction (in dry mass) in the mixture; $w_{\mathrm{m}}$ is the water content of the mixture; $w_{\mathrm{a}}$ is the water content of additive; $G_{\mathrm{sa}}$ is the specific gravity of additive.

For the bentonite/sand mixture, the water content of inactive sand was regarded as zero and the bentonite dry density could be calculated directly using Eq. (1). The variations of swelling pressure of bentonite/sand mixture with dry density of MX80 [3-4], Calcigel [5], Tsukinuno [6] and GMZ [7-8] are shown in Fig. 4. A unique relationship could be identified for each bentonite/sand mixture regardless of the bentonite fraction, suggesting that the swelling pressure was totally governed by the final bentonite dry density.

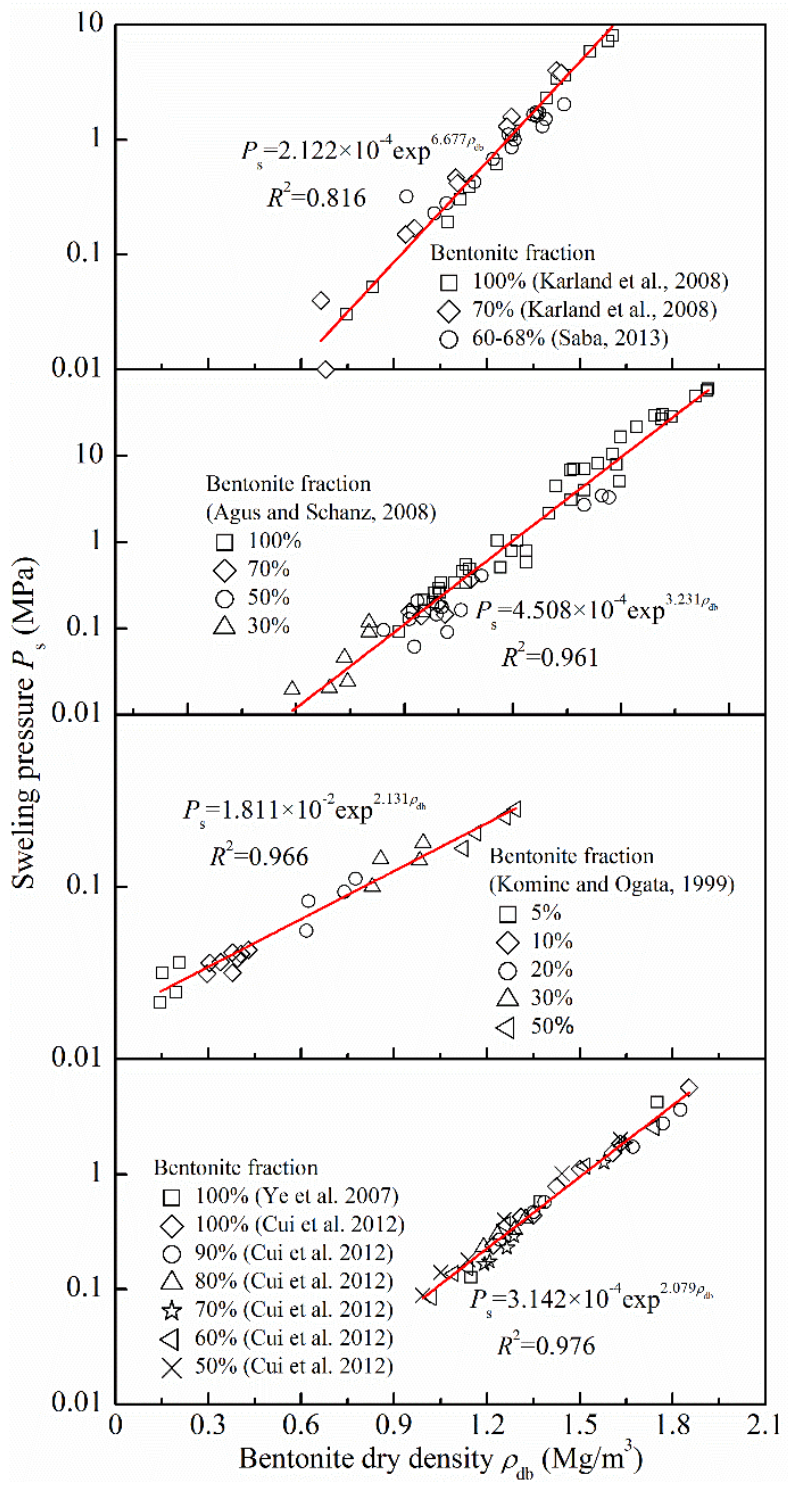

Fig. 4. Relationship between swelling pressure and bentonite dry density for bentonite/sand mixture: (a) MX80 bentonite; (b) Calcigel bentonite; (c) Tsukinuno bentonite; (d) GMZ bentonite. 
For the MX80 bentonite/claystone mixture, Wang et al. [10] assumed that the water content of claystone kept constant during wetting, and the water added was totally absorbed by bentonite. Following this assumption, the bentonite dry density could be calculated directly according to Eq. (1). The final swelling pressure versus bentonite dry density of the MX80 bentonite/claystone mixture is illustrated in Fig. 5. Other data obtained on the same materials are also plotted in the figure for comparison. It clearly showed that the relationship between swelling pressure and bentonite dry density for MX80 bentonite/claystone mixture depended on the bentonite fraction. When the bentonite fraction was larger than $70 \%$, the final swelling pressure followed a unique relationship with the bentonite dry density, which was almost the same as that for the MX80 bentonite/sand mixture. This observation suggested that claystone in the mixture with a large bentonite fraction worked as inactive sand and the swelling of claystone was totally inhibited by the bentonite. However, as the bentonite fraction is smaller than $70 \%$, the final swelling pressure deviated gradually from the above relation, and an additional contribution of claystone to the final swelling pressure became discernible. This suggested that for the bentonite/claystone mixture with a bentonite fraction lower than $70 \%$, the claystone grains could absorb water and swell in volume, contributing to the global swelling pressure.

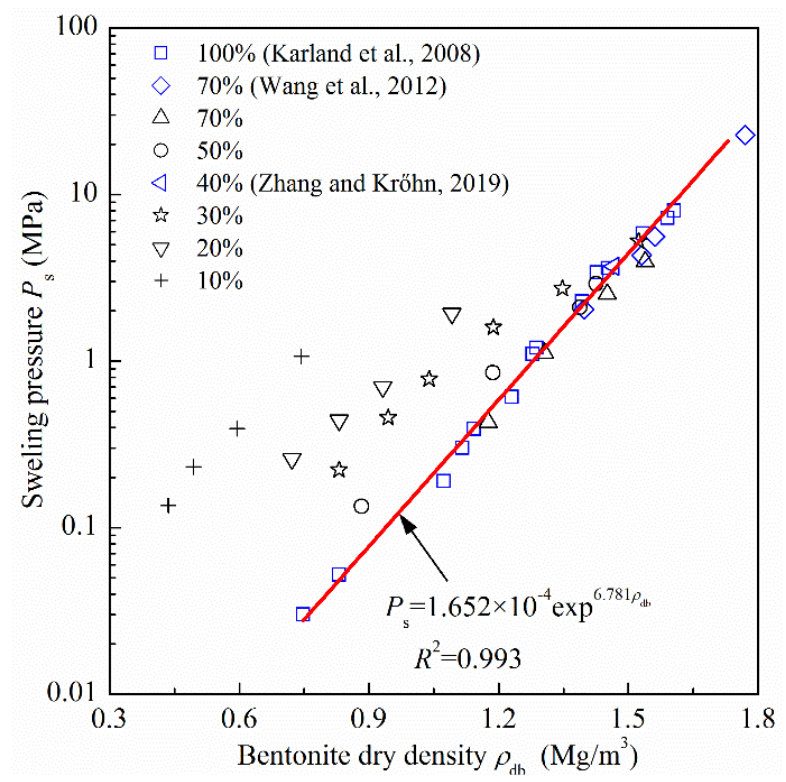

Fig. 5. Relationship between swelling pressure and bentonite dry density calculated by assuming constant water content of claystone.

\section{Conclusion}

The effects of bentonite fraction and dry density on the swelling pressure of MX80 bentonite/COx claystone mixture were experimentally studied, allowing the role and contribution of claystone to the global swelling pressure of its mixture with bentonite to be identified. Based on the obtained results, the following conclusions can be drawn:

- As the dry density and bentonite fraction of bentonite/claystone mixture decreased, the swelling pressure decreased, suggesting that the addition of claystone decreased the swelling capacity of bentonite/claystone mixture.

- For the bentonite/claystone mixture with less than $30 \%$ claystone, the swelling of claystone was inhibited by the bentonite and the claystone behaved as inert sand without any contribution to the global swelling pressure. By contrast, for the mixture with more than $30 \%$ claystone, claystone could swell and significantly contribute to the global swelling pressure.

\section{Acknowledgements}

The authors would like to thank the China Scholarship Council (CSC) and French National Agency for Nuclear Waste Management (ANDRA) for their financial support. They would also gratefully acknowledge the helpful support provided by the Ecole des Ponts ParisTech.

\section{References}

1. H. Menaceur, P. Delage, A.M. Tang, J. Talandier, Rock Mech. Rock Eng., 49, 12, 4571-4586 (2016)

2. O. Cuisinier, F. Masrouri, M. Pelletier, F. Villieras, R. Mosser-Ruck, Appl. Clay. Sci., 40, 1-4, 159-170. (2008)

3. S. Saba, PhD Thesis, Université Paris-Est, (2013)

4. O. Karnland, U. Nilsson, H. Weber, P. Wersin, Phys. Chem. Earth Parts A/B/C, 33, S472-S475 (2008)

5. S.S. Agus, T. Schanz, Acta Geotech., 3, 2, 125. (2008)

6. H. Komine, N. Ogata, Soils Found., 39, 2, 83-97 (1999)

7. S.L. Cui, H.Y. Zhang, M. Zhang, Eng. Geol., 141, 65-73 (2012)

8. W.M. Ye, T. Schanz, L.X. Qian, J. Wang, Y. Arifin, Chin. J. Rock Mech. Eng. 26, S2, 3861-3865 (2007)

9. C.S. Tang, A.M. Tang, Y.J. Cui, P. Delage, C. Schroeder, E. De Laure, Phys. Chem. Earth Parts A/B/C 36, 17-18, 1857-1866 (2011)

10. Q. Wang, A.M. Tang, Y.J. Cui, P. Delage, B. Gatmiri, Eng. Geol., 124, 59-66 (2012)

11. A.M. Tang, Y.J. Cui, T.T. Le, Appl. Clay. Sci., 41, 3-4: 181-189 (2008)

12. Z.X. Zeng, Y.J. Cui, F. Zhang, N. Conil, J. Talandier, Appl. Clay. Sci., 178, 105137 (2019)

13. O. Fouché, H. Wright, J.M. Le Cléac'h, P. Pellenard, Appl. Clay. Sci., 26, 1-4, 367-387 (2004)

14. C.L. Zhang, K.P. Kröhn, Geomech. Energy Environ., 17, 90-105 (2019)

15. Q. Wang, A.M. Tang, Y.J. Cui, P. Delage, J.D. Barnichon, W.M. Ye, Soils Found., 53, 2, 232-245 (2013) 